\title{
SYSTOLIC VENTRICULAR INTERACTION IN NORMAL AND DISEASED EXPLANTED HUMAN HEARTS
}

James P. Slater, $\mathrm{MD}^{\mathrm{a}}$

Evan C. Lipsitz, MD ${ }^{\mathrm{a}}$

Jonathan $\mathrm{M}$. Chen, $\mathrm{MD}^{\mathrm{a}}$

Howard R. Levin, MD $^{\mathrm{b}}$

Mehmet C. Oz, $\mathrm{MD}^{\mathrm{a}}$

Daniel J. Goldstein, $\mathrm{MD}^{\mathrm{a}}$

Robert C. Ashton, $\mathrm{MD}^{\mathrm{a}}$

Daniel Burkhoff, $\mathrm{MD}^{\mathrm{b}}$
Objective: The purpose of this study was to quantify the magnitude of interaction between the right and left ventricles in conditions of heart failure. Methods: Human hearts were taken from transplant recipients diagnosed with dilated cardiomyopathy at the time of transplantation and were restored to beating condition with use of an isolated perfusion circuit. Left ventricular-right ventricular interaction was determined by ramping volume in the left ventricle while holding right ventricular volume constant. Right ventricular pressure gain was plotted against left ventricular pressure and the slope of the linear regression determined the left ventricularright ventricular interaction. A similar procedure was used to determine right ventricular-left ventricular interaction. Two normal hearts were obtained from transplant donors not suitable for cardiac donation to serve as control hearts. Results: Mean left ventricular-right ventricular interaction was 0.22 in the hearts with dilated cardiomyopathy compared with 0.06 in the control hearts. Mean right ventricular-left ventricular interaction was 0.14 in the hearts with dilated cardiomyopathy compared with 0.09 in the control hearts. A marked increase in left ventricular-right ventricular interaction was noted in the hearts with dilated cardiomyopathy compared with control hearts. Although observed values of right ventricular-left ventricular interaction also correspond to previously published results, no significant increase was observed in the dilated cardiomyopathy condition. Conclusions: These studies confirm previously published values for systolic ventricular interaction obtained with animal models and demonstrate a marked increase in the dependence of the right ventricle on left ventricular function to maintain systolic pressure generation during conditions of dilated cardiomyopathy. (J Thorac Cardiovasc Surg 1997;113:1091-9)
$\mathrm{D}$ eterminants, mechanisms, and the magnitude of interaction between the right (RV) and left ventricles (LV) have been the subject of considerable study since first commented on by Bernheim ${ }^{1}$ in $1910 .^{2-6}$ Ventricular interactions are commonly divided into diastolic and systolic components. Diastolic ventricular interaction has been characterized

From the Departments of Surgery ${ }^{\text {a }}$ (Division of Cardiothoracic Surgery) and Medicine ${ }^{\mathrm{b}}$ (Division of Circulatory Physiology), Columbia University College of Physicians and Surgeons, New York, N.Y.

Received for publication August 30, 1996; revisions requested Oct. 11, 1996; revisions received Nov. 5, 1996; accepted for publication Nov. 11, 1996.

Address for reprints: Daniel Burkhoff, MD, Department of Medicine, 630 West 168th St., New York, NY 10032.

Copyright (C) 1997 by Mosby-Year Book, Inc.

$0022-5223 / 97 \$ 5.00+0 \quad \mathbf{1 2} / \mathbf{1} / 79184$ as alteration in ventricular configuration caused by volume changes in the contralateral ventricle transmitted through the interventricular septum. ${ }^{7}$ These effects are largely inhibitory to the function of the affected ventricle. In contrast, systolic effects have been noted to be predominantly contributory to function. Early studies on systolic ventricular interaction demonstrated that destruction or replacement of the RV had little effect on RV pump function. ${ }^{8-14}$ Bakos $^{11}$ hypothesized that RV function is maintained by contribution of the LV. Subsequent studies have demonstrated that both ventricles augment function of the contralateral ventricle to some degree. $^{2,5,6,15}$ Several investigators, using in vivo and isolated heart preparations, have attempted to quantify the magnitude of systolic ventricular interaction in normal hearts in terms of pressure gain. ${ }^{16-18}$ This work has been limited to animal models. Attempts have also been made to charac- 
terize ventricular interaction in various disease states with the use of similar models. ${ }^{19-21}$

To determine the magnitude of ventricular interaction in conditions of heart failure, four human hearts were obtained at the time of transplantation from patients with dilated cardiomyopathy (DCM). With the use of a previously described isolated perfusion circuit $^{22,23}$ we restored these hearts to a beating condition and performed measurements of ventricular interaction. In addition, two hearts with normal function, but not suitable for transplantation, were obtained and served as control hearts.

\section{Methods}

We have previously described the restoration of explanted human hearts to a beating condition and demonstrated the stability of this preparation for hemodynamic studies. $^{22}$

Organ procurement and preparation. Hearts with DCM were obtained from participants in the cardiac transplant program at the Columbia-Presbyterian Medical Center. All patients underwent standard evaluation before acceptance into the program, including detailed demographic profile, echocardiography or gated blood pool scan, and cardiac catheterization. Control hearts were obtained from organ donors ineligible for cardiac donation because of age constraints only (age $>65$ years). Preharvest cardiac function was determined by transthoracic echocardiography and judged to be normal. This study was done with the approval of our Institutional Review Board.

Patients with DCM ( $n=4)$ were operated on for the purpose of orthotopic cardiac transplantation. Patients were anesthetized, and cardiopulmonary bypass was established in standard fashion. Hearts were arrested with a $10 \mathrm{ml} / \mathrm{kg}$ dose of $4: 1$ blood/crystalloid $(120 \mathrm{mg} \mathrm{KCl}, 12.5$ gm mannitol, $\mathrm{HCO}_{3}$ ) cardioplegic solution administered through an aortic cannula after application of the aortic crossclamp. Hearts were explanted with the majority of atrial tissue and ascending aorta left in situ. The hearts were cooled to $4^{\circ} \mathrm{C}$ by immediate immersion in an iced saline solution bath in the operating room to minimize warm ischemic time. All subsequent preparation was done with the heart in this bath.

Techniques previously described were used to prepare the hearts. ${ }^{22,23}$ Chordae tendineae were left intact. Oblong-shaped brass rings were sutured to the mitral and tricuspid annuli. Once positioned these rings blocked both the LV and RV outflow tracts. These rings were fitted with cuffs that positioned the heart on a volume servo system (discussed later). Size 14F and 12F DeBakey coronary perfusion cannulas (C. R. Bard Inc., Tewksbury, Mass.) were inserted into the right and left coronary ostia, respectively. A Gundry retrograde coronary sinus perfusion catheter (DLP, Grand Rapids, Mich.) was inserted into the coronary sinus and the balloon inflated. The heart was then transported to the 1aboratory in the water bath.

Control hearts $(n=2)$ were harvested from organ donors with the use of previously published techniques. ${ }^{24}$
Hearts were arrested with University of Wisconsin solution and transported to the lab in a $4^{\circ} \mathrm{C}$ University of Wisconsin solution bath. Hearts were then instrumented and prepared as described above.

Perfusion system. The perfusion circuit was an open system similar to that previously described and is illustrated in Fig. 1.22 The system consisted of a COBE Ultra CMV membrane oxygenator with cardiotomy reservoir containing a $30 \mu \mathrm{m}$ filter (COBE, Arvada, Colo.), a circulating water bath, a hollow fiber dialysis tubing cartridge (COBE), a roller head pump (Sarns, Ann Arbor, Mich.), an in-line CDI $\mathrm{pH}$ and temperature meter (Sarns), and $1 / 4$-inch and $1 / 2$-inch connective tubing. The total circuit volume was $600 \mathrm{ml}$.

Coronary venous blood drained spontaneously through the coronary sinus catheter and thebesian flow drained through stab wounds in the RV and LV, all of which was collected in a large funnel and directed to the cardiotomy reservoir where it was warmed by an internal heating element via the water bath. The blood was then drawn from the reservoir by the roller head pump and passed through the dialysis cartridge on its return to the membrane oxygenator. This oxygenated blood was pumped to the cannulas in the coronary arteries or coronary sinus.

The system was primed with $750 \mathrm{ml}$ Dianeal low calcium $(2.5 \mathrm{mg} / \mathrm{L})$ peritoneal dialysis solution with $1.5 \%$ dextrose (Baxter, Deerfield, Ill.) and debubbled. To the prime was added 2 units of recently outdated, typespecific, noncrossmatched packed red blood cells. The red blood cells were washed to remove excess potassium and citrate by being mixed with $250 \mathrm{ml}$ normal saline solution and centrifuged at $4400 \mathrm{rpm}$ for 5 minutes and then decanted. Two hundred units of heparin and $300 \mathrm{mg}$ of calcium gluconate were added to each unit of packed cells. An additional 1000 units of heparin was added to the circuit. The prime was recirculated through the system against a heated water bath and the perfusate allowed to come to $37^{\circ} \mathrm{C}$.

Before the heart was reperfused corrective measures were required to adjust the potassium concentration, $\mathrm{pH}$, and calcium concentration of the perfusate to make the solution physiologic. The perfusate was dialyzed against the same dialysis fluid used in the prime supplemented with $600 \mathrm{mg}$ of calcium gluconate. Initially no potassium was added to the system and the perfusate was dialyzed to a potassium concentration of less than $1.5 \mathrm{mEq} / \mathrm{ml}$. Once this low potassium concentration was achieved approximately $2 \mathrm{mEq}$ of potassium was added directly to the prime and an additional $2 \mathrm{mEq} / \mathrm{L}$ of potassium was added to the dialysate. This resulted in a potassium concentration of 3.5 to $4.5 \mathrm{mEq} / \mathrm{L}$ in the perfusate, which was maintained throughout the experiment. Initial $\mathrm{pH}$ measurements were acidotic ( $\mathrm{pH} 6.5$ ) because of the composition of the dialysis fluid and stored blood. This was corrected and the $\mathrm{pH}$ maintained by the addition of approximately $50 \mathrm{mEq}$ sodium bicarbonate directiy to the perfusate. Similarly, calcium gluconate was added to the dialysate to maintain an ionized calcium level of approximately $0.9 \mathrm{mEq} / \mathrm{L}$. Electrolyte and $\mathrm{pH}$ values were monitored throughout the experiment with use of a Nova Stat Profile 5 instrument (Nova Biomedical Inc., Waltham, Mass.) and the in-line CDI monitor. Activated clotting 


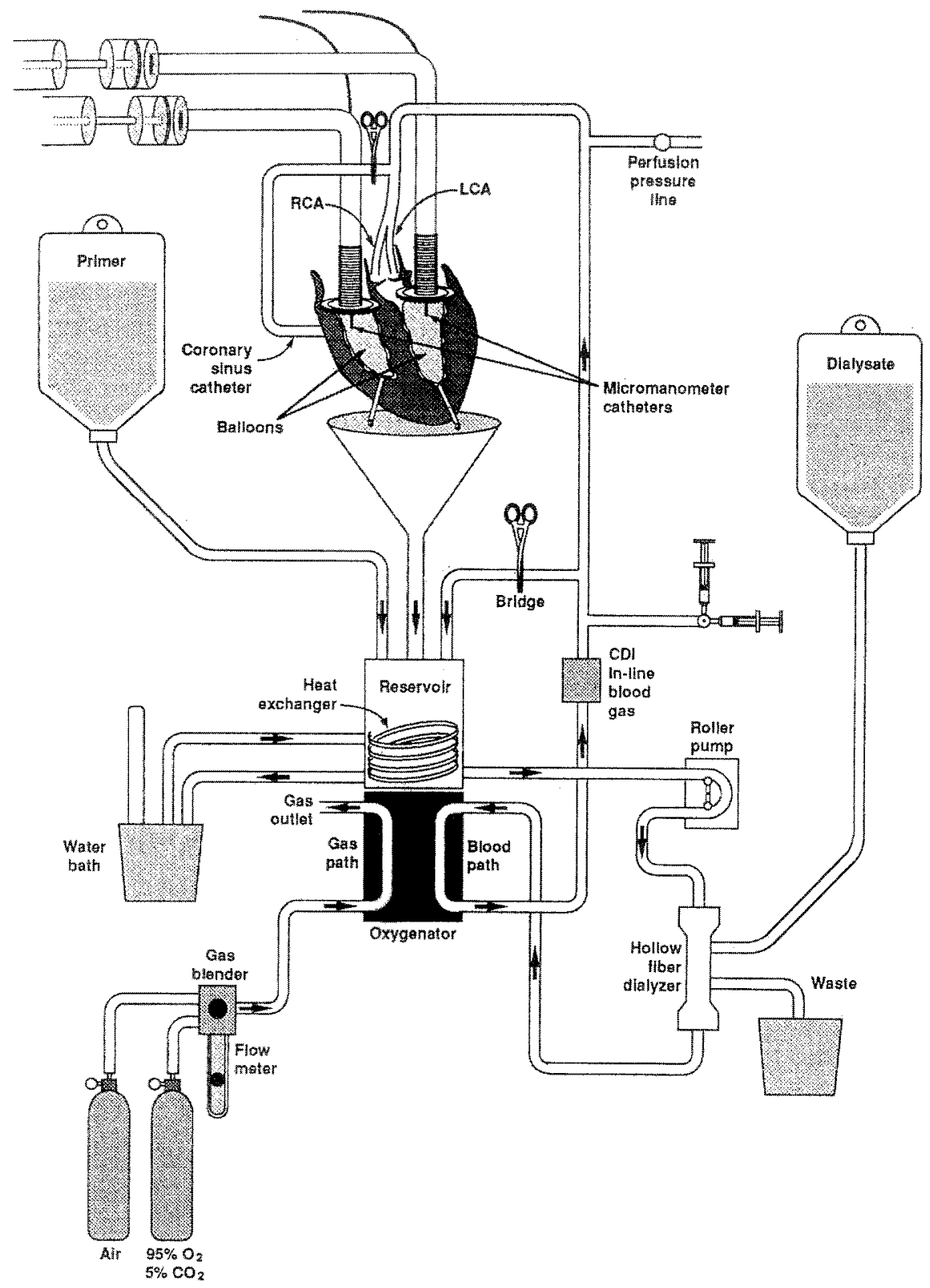

Fig. 1. Isolated blood perfusion circuit. Direction of blood flow is indicated. $R C A$, Right coronary artery; $L C A$, left coronary artery.

time determinations just before reperfusion were greater than 200 seconds and remained at this level for the duration of the experiment.

The perfusate was oxygenated through the membrane oxygenator with an admixture of compressed air and carbogen ( $95 \%$ oxygen, $5 \%$ carbon dioxide). The sweep gas and percent carbogen were adjusted to maintain a carbon dioxide tension of 30 to 34 torr. The hemoglobin oxygen saturation was $100 \%$ throughout the experiment as determined by periodic blood gas determinations.

The apparatus as just described was prepared in the physiology laboratory before explantation of the heart.
When the heart was brought to the laboratory all blood parameters had been corrected and were within physiologic range. In this manner, the heart could be reperfused immediately on its arrival to minimize ischemic time.

Servo system. After surgical preparation, hearts were connected to RV and LV volume servo control systems. Details of their design have been reported previously. 25,26 In brief, motor-driven piston pumps regulate the volume of a balloon placed within each ventricular chamber (Fig. 1). The mitral and triscuspid rings serve to confine the balloon within the respective ventricular chamber. This system therefore provides the means to measure and 


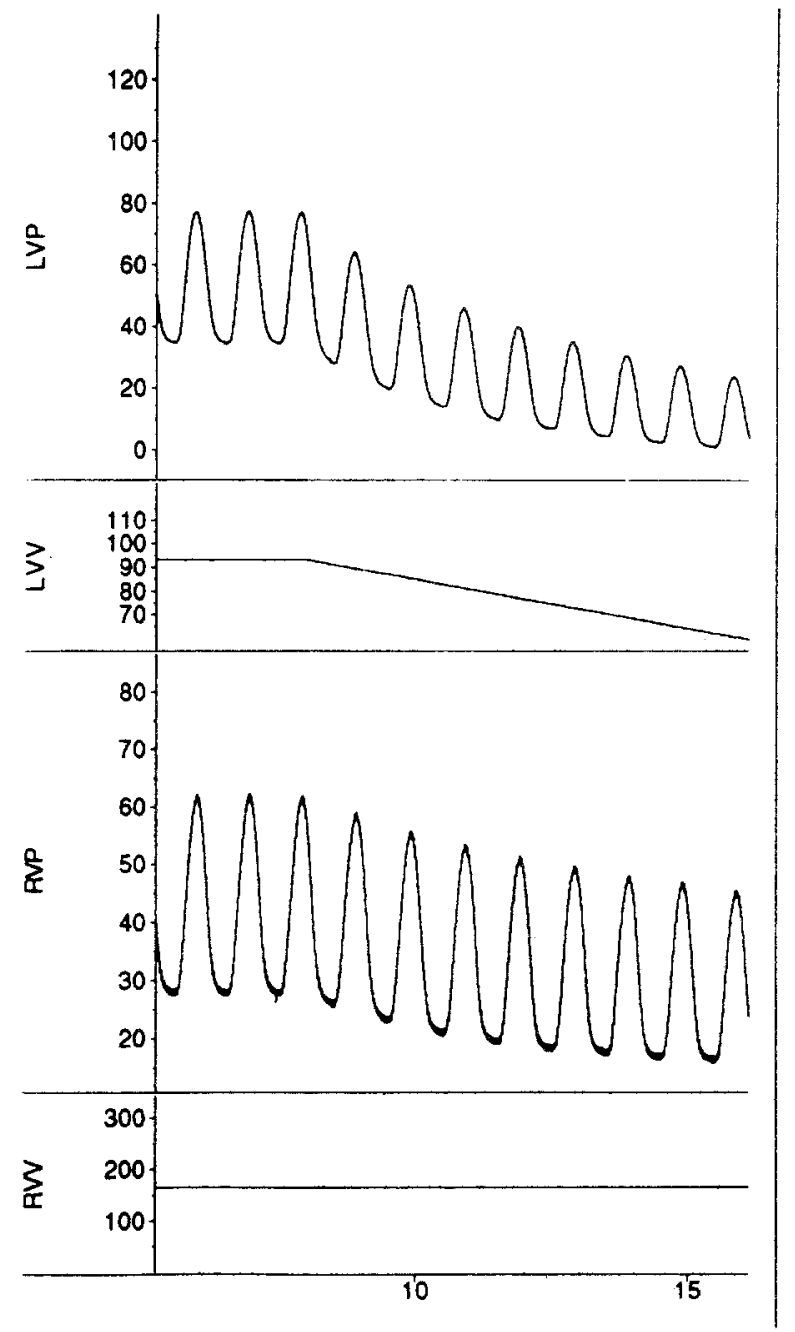

Time (secs)

Fig. 2. Representative data from heart with DCM. LVP, LV pressure; $L V V$, LV volume; $R V P$, RV pressure; $R V V$, RV volume.

control ventricular volume. In addition, a micromanometer sensor inside each balloon is used to measure intraventricular pressure. Both RV and $L V$ volume servo systems are controlled by a computer, which is programmed either to impose physiologic ejection and filling flow patterns or to constrain the ventricles to contract isovolumetrically as required by the protocol. Details of the design of this computer-controlled system are similar to those described previously. ${ }^{27,28}$

Reperfusion. The heart was initially reperfused in retrograde fashion via the coronary sinus catheter to remove air from the coronary arteries. After a short time retrograde perfusion was stopped, the coronary sinus balloon was deflated and opened to air, and antegrade flow was initiated. Several hearts fibrillated initially on rewarming and required electric cardioversion with ventricular pacing. These hearts restarted after one 30 -joule shock only.
All hearts were paced via pacing wires inserted into the LV apex. Temperature was maintained between $35^{\circ}$ and $37^{\circ} \mathrm{C}$ by use of a circulating water bath and was monitored by both an epicardial surface probe and the in-line CDI temperature monitor. Time from explantation to the return to beating condition was approximately 40 minutes in all cases.

Protocol. Hearts were restored to a beating condition. RV volume was fixed to provide an $R V$ end-diastolic pressure of $20 \mathrm{~mm} \mathrm{Hg}$. LV volume was ramped from a volume that provided an LV end-diastolic pressure of 30 $\mathrm{mm} \mathrm{Hg}$ to a volume that provided an LV end-diastolic pressure of $0 \mathrm{~mm}$ Hg. Pressure was simultaneously measured in both the RV and LV during the volume ramp. Developed pressure values were determined by subtracting end-diastolic pressure from peak systolic pressure for each beat during the volume ramp. RV developed pressure was plotted against LV developed pressure for the entire LV volume ramp. Linear regression was used to characterize the relationship between RV and LV developed pressures. The slope of the resulting line defined the magnitude of left-to-right ventricular interaction (LVRVI). This slope quantifies the pressure gain in the RV caused by an increase in pressure in the $\mathrm{LV}$. The analogous, opposite procedure was used to determine RV-LVI.

In two hearts (1 normal, $1 \mathrm{DCM})$, epinephrine $(1 \mathrm{mg})$ was administered to the perfusate to study the effects of inotropes on LV-RVI.

Data were digitized in real time at a speed of $200 \mathrm{~Hz}$ by an analog-digital converter (MacLab/8, model Mac Lab MkIII, ADInstruments, Ply Ltd., Australia), filtered with a $50 \mathrm{~Hz}$ low-pass filter, and recorded by a Macintosh IIcx computer (Apple Computers Inc., Cupertino, Calif.). Blood gas determinations were done with a Nova Stat 3 Profile instrument.

\section{Results}

Representative data that demonstrate the effect of ramping $\mathrm{LV}$ volume on $\mathrm{RV}$ pressure in a heart with DCM are shown in Fig. 2.

The slope of the RV pressure versus LV pressure plot defines LV-RVI. LV-RVI ranged from 0.18 to 0.26 in the hearts with DCM. Mean LV-RVI was $0.22 \pm 0.03$ (standard deviation) for the hearts with DCM. LV-RVI was 0.04 and 0.08 in the control hearts (mean $0.06 \pm 0.03$ ). LV-RVI is plotted for each heart in Fig. 3.

Similarly, RV-LVI is defined by the slope of the plot LV pressure versus RV pressure. RV-LVI ranged from 0.07 to 0.29 in the hearts with DCM (mean $0.14 \pm 0.1$ ). RV-LVI was 0.15 and 0.02 in the control hearts (mean $0.09 \pm 0.1$ ). The RV-LVI for each heart is plotted in Fig. 4.

The effect of inotropes on LV-RVI was studied by adding epinephrine to the perfusate for two hearts (1 normal, 1 DCM). In the normal heart LV-RVI was 0.041 without epinephrine and 0.047 with epi- 


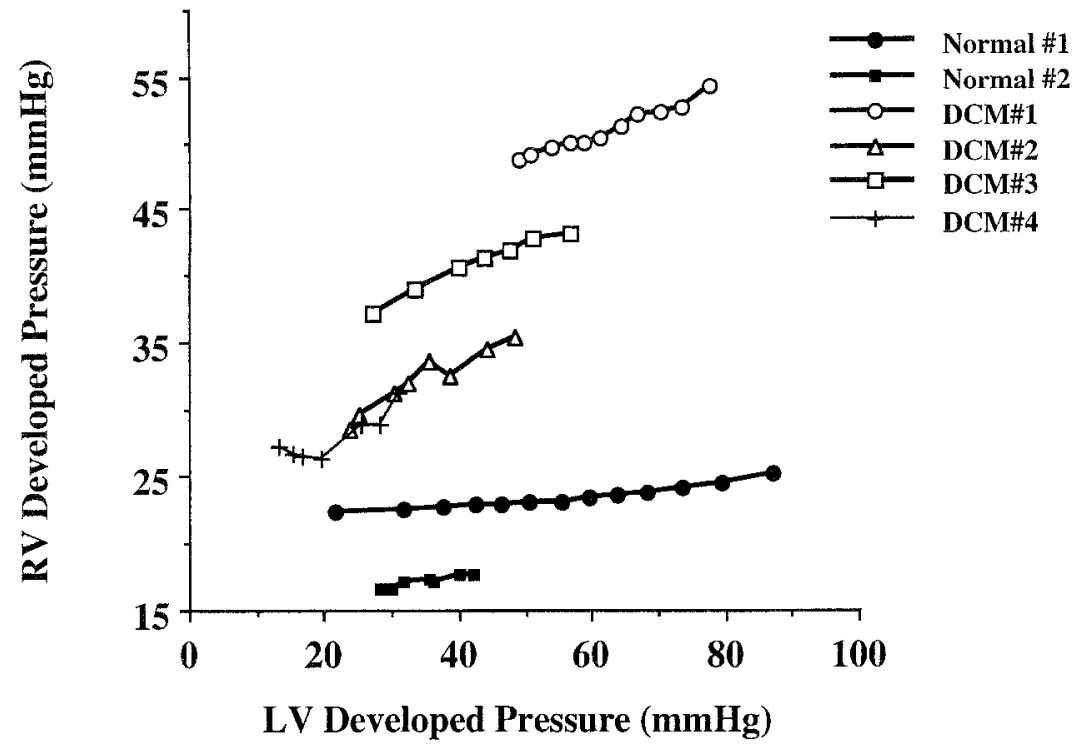

Fig. 3. RV pressure versus LV pressure (developed pressures) for two normal and four DCM hearts.

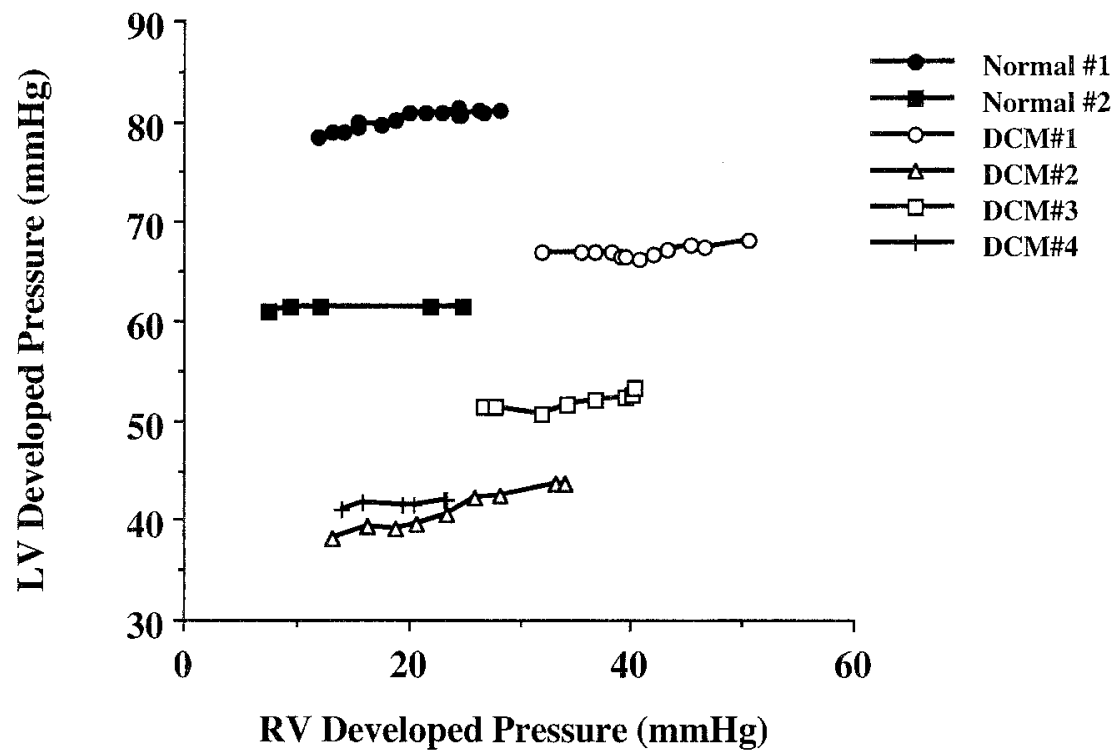

Fig. 4. LV pressure versus RV pressure (developed pressures) for two normal and four DCM hearts.

nephrine. In the heart with DCM LV-RVI was 0.26 without epinephrine and 0.15 with epinephrine. LV-RVI is plotted for both hearts in Fig. 5.

\section{Discussion}

The ventricles of the heart interact as two pumps in series through the pulmonary and systemic circulations. Muscle fibers common to both ventricular free walls and a shared distensible septum make up the anatomic basis for mechani- cal interaction between the ventricles not directly related to their in-series configuration. ${ }^{29}$ The effects of this interaction on pump function are noted to be different in diastole than in systole. In diastole the sum total of mechanical ventricular interaction is thought to be inhibitory to pump function. Distention in one ventricle causes septal shift in the opposite direction, which has a negative impact on diastolic filling in the contralateral ventricle. $3,4,15,18,30$ Conversely, the overall ef- 


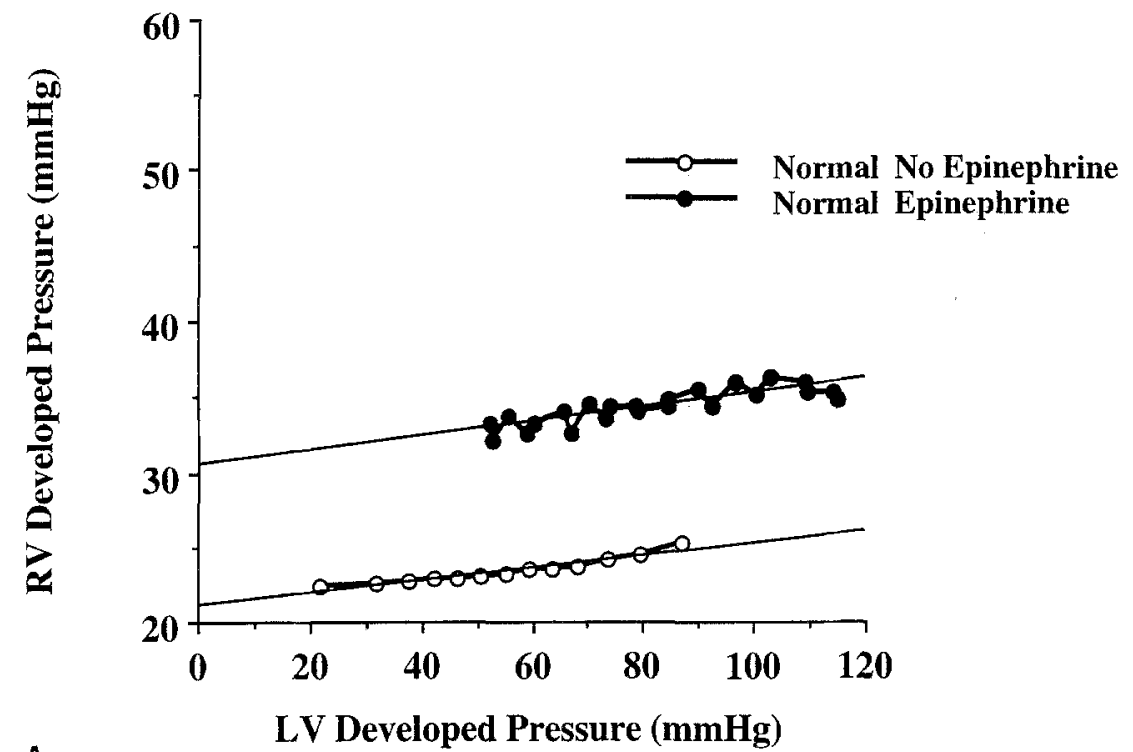

A

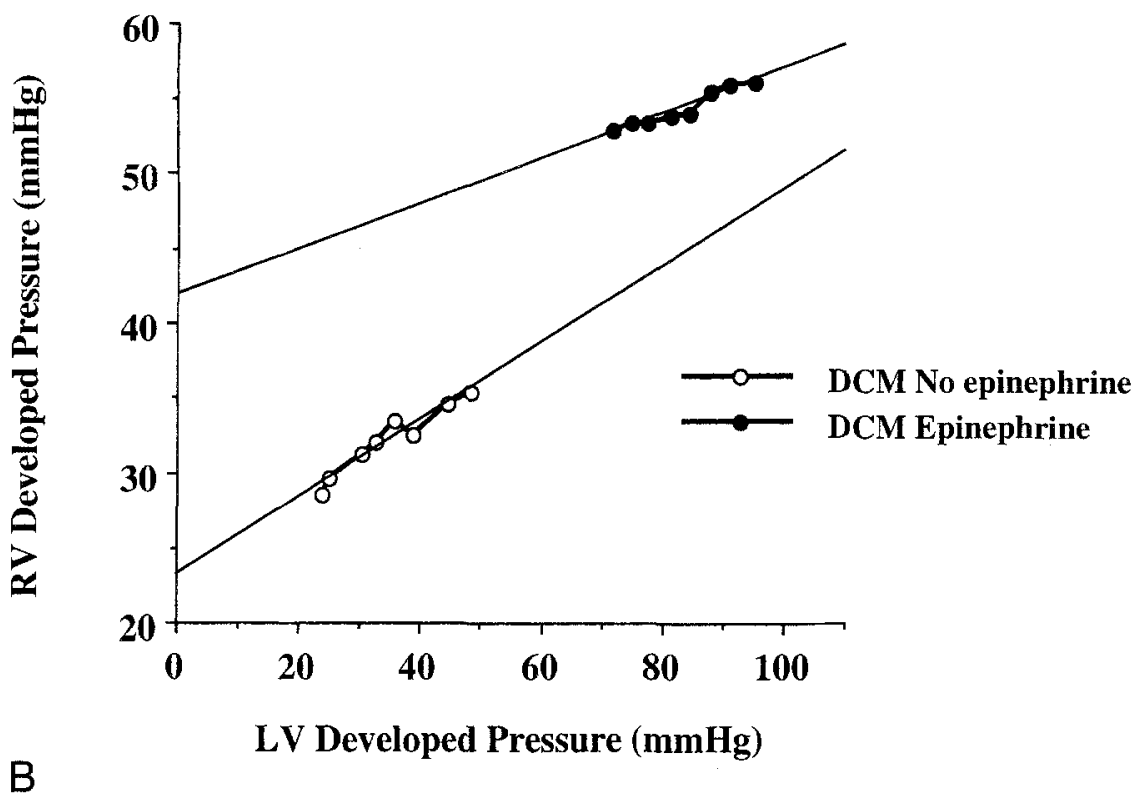

Fig. 5. Effects of epinephrine on LV-RVI on (A) normal and (B) DCM hearts.

fects of systolic ventricular interaction have been shown to be contributory to pump function.

Previously, investigators have attempted to quantify the magnitude of systolic ventricular interaction. This work has been done solely in animal models with both in vivo and isolated heart preparations. The majority of these studies measured pressure in one ventricle at constant volume while abruptly varying volume in the contralateral ventricle. Pressure gain was then determined by plotting the change in pressure in the volume-constant ventricle over the change in pressure in the volume-varied ventricle. Maughan, Sunagawa, and Sagawa ${ }^{16}$ first suggested that there would be a directional dependence of ventricular interaction and used a threecompartment volume elastance model to predict that RV-LVI would be greater than LV-RVI. The model prediction was confirmed by actual measurement. ${ }^{16}$ The theoretic basis for this model is that ventricular interaction is dependent on the elastances of the two ventricular free walls and the interventricular septum. ${ }^{16}$ Normal canine hearts in an isolated preparation were used to determine an LV-RVI value of 0.08 and an RV-LVI value of 
Table I. Previously published values of systolic ventricular interaction in various models

\begin{tabular}{lllcc}
\hline \multicolumn{1}{c}{ Author } & \multicolumn{1}{c}{ Model } & Condition & LV-RVI & RV-LVI \\
\hline Maughan $^{16}$ & Canine/isolated & Normal & 0.080 & 0.15 \\
Yamaguchi $^{17}$ & Canine/in vivo & Normal & 0.040 & 0.1 \\
Woodard $^{18}$ & Porcine/in vivo & Normal & 0.054 & NR \\
Farrar $^{21}$ & Porcine/in vivo & Normal & 0.040 & NR \\
Farrar $^{21}$ & Porcine/in vivo & Cardiomyopathy & 0.103 & NR \\
Slater & Human/isolated & Normal & 0.060 & 0.09 \\
Slater & Human/isolated & Cardiomyopathy & 0.220 & 0.14 \\
\hline
\end{tabular}

$N R$, Not reported.

$0.15{ }^{16}$ In an in vivo, open-chest canine preparation Yamaguchi and coworkers ${ }^{17}$ determined a mean LV-RVI of 0.04 and a mean RV-LVI of 0.10 . These values were in concert with the findings of Maughan, Sunagawa, and Sagawa. ${ }^{16}$ Yamaguchi and cowork$\mathrm{ers}^{17}$ demonstrated that the magnitude of ventricular interdependence is not constant through systole, but varies throughout the cycle. ${ }^{17}$ Yamaguchi and coworkers ${ }^{17}$ also importantly noted that although RV-LVI is greater than LV-RVI in magnitude, when taken as percent contribution to pressure generation LV-RVI is much more important to RV pressure generation ( $20 \%$ to $40 \%$ ) than RV-LVI is to LV pressure generation (4\% to $11 \%$ ). ${ }^{17}$ Woodard, Chow, and Farrar ${ }^{18}$ confirmed the findings of Yamaguchi and coworkers ${ }^{17}$ of a varying magnitude of ventricular interaction through systole and in an openchest porcine model determined a mean LV-RVI value of 0.054 . This study also showed that, in addition to decreased RV pressure, RV stroke volume and stroke work were diminished as a result of LV-RVI. ${ }^{18}$ A summary of previously published values of LV-RVI and RV-LVI is presented in Table I.

The three-component elastance model of Maughan, Sunagawa, and Sagawa ${ }^{16}$ suggests that changing elastance, particularly in the septum, has an impact on the magnitude of ventricular interaction. ${ }^{16}$ This concept was supported by Santamore and Burkhoff ${ }^{31}$ who incorporated it into a computer model of ventricular interdependence in which elastance could be varied. This model was used to demonstrate that when septal elastance is extremely low (that is, thin-walled septum) LV-RVI is increased, whereas when septal elastance is high (that is, thick-walled septum) LV-RVI is negligible. ${ }^{31}$ Little, Badke, and O'Rourke ${ }^{19}$ have previously shown in long-term dog studies that diastolic ventricular interaction is diminished in the presence of interventricular septal hypertrophy induced by RV pressure overload. Most recently Farrar, Woodard, and $\mathrm{Chow}^{21}$ have used a previously validated model of pacing-induced biventricular failure in open-chest pigs to study systolic interventricular interaction in disease states. In this study LV-RVI measured in control animals (LV-RVI $=0.040$ ) was comparable to that in their own previous work ${ }^{18}$ and the work of others. ${ }^{16,17}$ In the animals with heart failure, however, LV-RVI was increased $(\mathrm{LV}-\mathrm{RVI}=0.103$ ) dramatically to 2.5 times that of normal animals. ${ }^{21}$ Farrar, Woodard, and Chow ${ }^{21}$ accept the Santamore and Burkhoff ${ }^{31}$ model and conclude that decreased septal elastance, caused by dilated cardiomyopathy, results in the observed increase in LV-RVI.

In the present study we used human hearts for the first time to evaluate systolic ventricular interaction in both healthy and diseased states. Hearts with DCM were obtained from participants in the cardiac transplant program at the time of transplantation. Control hearts were obtained from organ donors with normal cardiac function ineligible for cardiac donation because of age constraints only. We used an isolated blood-perfused model that we recently described. ${ }^{22,23}$ Similar to previous studies we defined the magnitude of systolic ventricular interaction by the ratio of pressure change in the volume-constant ventricle to pressure change in the volume-varied ventricle. In the control hearts we observed a mean LV-RVI of 0.06 and a mean RV-LVI of 0.09 . These figures are in accordance with previously published values for animal-derived data (Table I). In the hearts with DCM we observed a mean LV-RVI of $0.22 \pm 0.03$, a threefold increase over LV-RVI values in the normal heart. This is consistent with the findings of Farrar, Woodard, and $\mathrm{Chow}^{21}$ in dilated porcine hearts. Our observed value for RV-LVI in normal hearts is also consistent with previously published values (Table I). No previously published values exist for RV-LVI in diseased hearts. In the hearts with DCM mean RV-LVI was $0.14 \pm$ 0.0 .1 , which represents a 1.5 -times increase over RV-LVI values in normal hearts. 
The present study not only confirms previously published values for systolic ventricular interaction, but also clearly demonstrates a marked increase in the dependence of the RV on LV function to maintain systolic pressure generation during conditions of DCM. This increased effect of LV function on RV performance is likely the result of decreased elastance of the interventricular septum as demonstrated by the Santamore-Burkhoff model. ${ }^{31}$ This is supported by the observation that increasing elastance, with the addition of epinephrine, resulted in a $60 \%$ reduction in LVRVI in the hearts with DCM, but had little effect in the normal heart. The modest increase in RV-LVI is likely the result of the same mechanism. These findings are further supported by the studies of Little, Badke, and O'Rourke, ${ }^{19}$ which demonstrated decreased systolic ventricular interaction in the presence of increased septal elastance.

There are several limitations to the current study. Because of the difficulty in obtaining both normal and diseased human hearts the number of hearts studied is suboptimal. Although systolic ventricular interaction has been shown to vary throughout the systolic cycle ${ }^{17,18,21}$ our measurements were made at one time only. In addition, by using a linear regression analysis to define the magnitude of ventricular interaction we have assumed that the interaction relationship is linear over a range of volumes, which may not be the case. The absence of pericardium has been shown to diminish ventricular interaction in both diastole and systole ${ }^{32-36}$; however, in a more recent study it was shown that the presence of pericardium increases diastolic but not systolic interactions. ${ }^{37}$ The absence of pericardium was not accounted for in our studies. Lastly, use of an isolated heart model may have an adverse impact on the geometry of the heart causing subtle changes in function inherent in our experiments.

In the present study we used normal and abnormal human hearts in an isolated perfusion model to study systolic ventricular interaction. We conclude that previously published values for LV-RVI and RV-LVI derived from animal models are comparable to those derived in human hearts. In addition, results of our experiments with diseased hearts are consistent with those of previously published reports that link systolic ventricular interaction with septal elastance. More specifically, in hearts with DCM $\mathrm{RV}$ function is approximately three times more dependent on LV function than is demonstrated for normal hearts.

\section{REFERENCES}

1. Bernheim PI. De l'asystolic veineuse dans l'hypertrophie du coeur gauche par stenose concomitante du ventricule droit. Rev Med 1910;39:785-94.

2. Oboler AA, Keefe JF, Gaasch WH, Banas JS, Levine JH. Influence of left ventricular isovolumic pressure upon right ventricular transients. Cardiology 1973;58:32-44.

3. Elzinga $G$, van Grondelle $R$, Westerhof $N$, et al. Ventricular interference. Am J Physiol 1974;226:941-7.

4. Santamore WP, Lynch PR, Meier GM, Heckman J, Bove AA. Myocardial interaction between the ventricles. J Appl Physiol 1976;41:362-8.

5. Santamore WP, Lynch PR, Heckman IL, Bove AA, Meier GD. Left ventricular effects on right ventricular developed pressure. J Appl Physiol 1976;41:925-30.

6. Langille BL, Jones DR. Mechanical interaction between the ventricles during systole. Can J Physiol Pharmacol 1977;55: 373-82.

7. Bove AA, Santamore WP. Ventricular interdependence. Prog Cardiovase Dis 1981;23:365-88.

8. Starr I, Jeffers WA, Mease RH. The absence of conspicuous increments of venous pressure after severe damage to the right ventricle of the dog, with discussion of the relation between clinical and congestive heart failure and heart disease. Am Heart J 1943;26:291-301.

9. Kagan A. Dynamic responses of the right ventricle following extensive damage by cauterization. Circulation 1952;5:81623.

10. Donald DE, Essex HE. Pressure studies after inactivation of the major portion of the canine right ventricle. Am J Physiol 1954;176:155-61.

11. Bakos ACP. The question of the function of the right ventricular myocardium: an experimental study. Circulation 1950;1:724-32.

12. Seki S, Ohba O, Tanizaki $\mathrm{M}$, et al. Construction of a new right ventricle on the epicardium: a possible correction for underdevelopment of the right ventricle. J Thorac Cardiovasc Surg 1975;70:330-7.

13. Seki S, Ono K, Tanizaki M, et al. Role of contraction and size of right ventricular free wall in performance of the heart. Jpn J Thorac Surg 1977;29:731-4.

14. Sawatani S, Mandell C, Kusaba E, et al. Ventricular performance following ablation and prosthetic replacement of right ventricular myocardium. Trans Am Soc Artif Intern Organs 1974;20:629-36.

15. Santamore WP. Mechanical interaction between the left and right ventricles [Doctoral Thesis]. Philadelphia: Temple University, 1975.

16. Maughan WL, Sunagawa K, Sagawa K. Ventricular systolic interdependence: volume elastance model in isolated canine hearts. Am J Physiol 1987;253:H1381-90.

17. Yamaguchi S, Harasawa H, Li KS, Zhu D, Santamore WP. Comparative significance in systolic ventricular interaction. Cardiovasc Res 1991;25:774-83.

18. Woodard JC, Chow E, Farrar DJ. Isolated ventricular systolic interaction during transient reductions in left ventricular pressure. Circ Res 1991;70:944-51.

19. Little WC, Badke FR, O'Rourke RA. Effect of right ventricular pressure on the end diastolic left ventricular pressurevolume relationship before and after chronic right ventricular pressure overload in dogs without pericardia. Circ Res 1984;54:719-30. 
20. Slinker BK, Chagas ACP, Glantz SA. Chronic pressure overload hypertrophy decreases direct ventricular interaction. Am J Physiol 1987;253:H1062-75.

21. Farrar DJ, Woodard JC, Chow E. Pacing-induced dilated cardiomyopathy increases left-to-right-ventricular systolic interaction. Circulation 1993;88:720-5.

22. Slater JP, Lipsitz EC, Chen JM, Levin HR, Oz MC, Burkhoff $D$. Use of explanted human hearts as a model for the study of cardiac pathophysiologic conditions. J Thorac Cardiovasc Surg 1995;110:239-47.

23. Burkhoff D, Flaherty JT, Yue DT, et al. In vitro studies of isolated supported human hearts. Heart Vessels 1988;4:185-96.

24. Smith CR. Techniques in cardiac transplantation. Prog Cardiovasc Dis 1990;32:383-404.

25. Suga $\mathbf{H}$, Sagawa $\mathbf{K}$. Instantaneous pressure-volume relationships and their ratio in the excised, supported canine left ventricle. Circ Res 1974;35:117-26.

26. Suga H, Sagawa K. End diastolic and end-systolic ventricular volume clamper for isolated canine heart. Am J Physiol 1974;223:H718-H22.

27. Sunagawa K, Burkhoff D, Lim KO, Sagawa K. Impedance loading servo pump system for excised canine ventricle. Am $\mathbf{J}$ Physiol 1982;243:H346-50.

28. Burkhoff D, Tyberg JV. Why does pulmonary venous pressure rise following the onset of left ventricular dysfunction: results of a theoretical analysis of acute heart failure. Am J Physiol 1993;265:H1819-28.

29. Streeter DD Jr. Gross morphology and fiber geometry of the heart. In: Berne RM, ed. Handbook of physiology. Vol. 1. Bethesda, Maryland: American Physiologic Society, 1979: 66-8.

30. Brinker JA, Weiss JL, Lappe DL, et al. Leftward septal displacement during right ventricular loading in man. Circulation 1980;61:626-33.

31. Santamore WP, Burkhoff D. Hemodynamic consequences of ventricular interaction as assessed by model analysis. Am J Physiol 1991;260:H146-57.

32. Janicki JS, Weber KT. Ventricular interaction pre and post pericardectomy. Fed Proc 1978:37:776

33. Glantz SA, Misbach GA, Moores WY, et al. The pericardium substantially affects the left ventricular diastolic pressure in dogs. Circ Res 1978;42:433-41.

34. Spadaro J, Bing OHL, Gaasch WH, et al. Pericardial modulation of right and left ventricular diastolic interaction. Circulation 1979;60:11-93.

35. Janicki JJ. Influence of the pericardium and ventricular interdependence on left ventricular diastolic and systolic function in patients with heart failure. Circulation 1990;81: III15-20.

36. Santamore WP, Shaffer T, Papa L. Theoretical model of ventricular interdependence: pericardial effects. Am J Physiol 1990;259(1 pt 2):H181-9.

37. Farrar DJ, Chow E, Brown CD. Isolated systolic and diastolic ventricular interactions in pacing-induced dilated cardiomyopathy and effect of volume loading and pericardium. Circulation 1995;92:1284-90.

\section{Availability of Journal back issues}

As a service to our subscribers, copies of back issues of The Journal of Thoracic and Cardiovascular Surgery for the preceding 5 years are maintained and are available for purchase from Mosby at a cost of $\$ 15.00$ per issue until inventory is depleted. The following quantity discounts are available: $25 \%$ off on quantities of 12 to 23 , and one third off on quantities of 24 or more. Please write to Mosby-Year Book, Inc., Subscription Services, 11830 Westline Industrial Drive, St. Louis MO 63146-3318, or call $800-453-4351$ or 314-453-4351 for information on availability of particular issues. If unavailable from the publisher, photocopies of complete issues may be purchased from UMI, 300 N. Zeeb Rd., Ann Arbor, MI 48106, 313-761-4700. 